\title{
Artelogie
}

artelogie Recherche sur les arts, le patrimoine et la littérature de l'Amérique latine

$14 \mid 2019$

Sensibilités : Arts, littératures et patrimoine en

Amérique latine

\section{Apresentação do Acervo Sandra Jatahy Pesavento do IHGRGS (Instituto Histórico e Geográfico do Rio Grande do Sul)}

Nádia Maria Weber Santos

\section{OpenEdition}

Journals

Edição electrónica

URL: http://journals.openedition.org/artelogie/4184

DOI: 10.4000/artelogie.4184

ISSN: 2115-6395

Editora

Association ESCAL

Refêrencia eletrónica

Nádia Maria Weber Santos, « Apresentação do Acervo Sandra Jatahy Pesavento do IHGRGS (Instituto Histórico e Geográfico do Rio Grande do Sul) », Artelogie [Online], 14 | 2019, posto online no dia 07 janeiro 2019, consultado o 13 setembro 2019. URL : http://journals.openedition.org/artelogie/4184 ; DOI : 10.4000/artelogie.4184

Este documento foi criado de forma automática no dia 13 Setembro 2019.

Association ESCAL 


\title{
Apresentação do Acervo Sandra Jatahy Pesavento do IHGRGS (Instituto Histórico e Geográfico do Rio Grande do Sul)
}

\author{
Nádia Maria Weber Santos
}

\section{Apresentação do Acervo Sandra Jatahy Pesavento do IHGRGS (Instituto Histórico e Geográfico do Rio Grande do Sul)}

\section{Introdução}

1 O arquivo pessoal Sandra Jatahy Pesavento (1946-2009) - Acervo SJP, como denominamos - está depositado no Instituto Histórico e Geográfico do Rio Grande do Sul (IHGRGS) desde final de 2014, por doação da família Pesavento. Desde então, passa pelas diversas fases de organização e acomodação do acervo. A equipe curatorial do Acervo SJP, constituída em meados de 2015, é responsável pela organização primária do acervo em seus diferentes momentos (triagem, limpeza, classificação - organização nas caixas, pastas, prateleiras e gavetas, descrição e divulgação -, realização de eventos e exposições). É composta pelos seguintes membros: Curadora - Dra. Nádia Maria Weber Santos (historiadora); Me. Anelda Oliveira (historiadora); Me Luciana Gransotto (Mestre em Bens Culturais); Dra. Hilda Jaqueline Fraga (historiadora), Lic. Francielle Garcia (historiadora); Lic. Simone Steigleder (conservadora e restauradora de bens culturais).

O material completo do Acervo, até agosto de 2019, abrange três fundos ou coleções: I Coleção Bibliográfica: a biblioteca da historiadora, estimada em 4 mil obras (este material não está catalogado ainda), II - Fundo Documental (estimado em 60 mil itens): o material de estudo e de pesquisa dos 40 anos de trabalho da professora e pesquisadora, compreendendo: II/1 - Pastas suspensas, caixas e gavetões com material de estudo de 40 
anos; II/2 - Arquivo digital: obras completas de SJP digitalizadas e II/3 - Arquivo especial de fichas manuscritas: fichário completo, com móvel, pertencente à historiadora, incluindo fichamento de jornais do século XIX e início do século XX do Rio Grande do Sul; II/4 - Documentos de viagens (Álbuns com fotografias de viagens; Diários de viagens [cadernetas e pequenos cadernos, desde 1975]); III - Documentos tridimensionais/acervo museológico: III/1 - Objetos de viagem (Caixas, pedras, vasos, imagens, etc.); III/2 Colares de Sandra Pesavento. Esta última parte que compõe o acervo museológico recém foi colocado à disposição pela família Pesavento e está em fase de inventário, através da elaboração de fichas individuais para dimensionar o acervo museológico e poder executar a gestão desta documentação, que inclui: higienização, guarda, conservação, expografia, produção de documentação, etc.

O acervo está apresentado e descrito no site do IHGRGS http://www.ihgrgs.org.br/, no seguinte caminho, havendo online o inventário provisório das caixas, pastas suspensas e gavetas: http://www.ihgrgs.org.br/ - IHG digital - Arquivo online - Acervo Sandra Jatahy Pesavento 2017. As obras digitalizadas da autora encontram-se no seguinte link http:// ihgrgs.org.br/\#SandraPesavento .

4 Entre final de 2014 e 2017, a família teve duas iniciativas importantes: a criação de um website sobre a historiadora e a digitalização completa de sua obra (livros individuais e capítulos de livros, perfazendo 121 itens). Com isto, proporcionam uma democratização no compartilhamento público de seus escritos: suas obras digitalizadas estão disponíveis, desde meados de 2017, junto ao website do IHGRGS e o site sobre ela foi colocado em linha em maio também de 2017, nele constando uma linha do tempo da pesquisadora, com imagens selecionadas pela família, incluindo sua vida pessoal e produção das obras, os inéditos carnets de Voyage, escritos em viagem a Paris em 2004, vídeos de entrevistas e fotos, livros individuais publicados e agora digitalizados. ${ }^{1}$

Uma mais recente iniciativa em curso (proposta pela família em janeiro de 2019) familiar está sendo a doação de objetos pertencentes à Sandra Pesavento (Fundo III, Museológico, conforme acima), a maioria trazida de viagens da historiadora, para o acervo. Não foram ainda dimensionados em quantidade e estão em vias de serem transportados ao arquivo para guarda e posterior classificação. Com isto, o acervo pessoal SJP está ganhando em potencialidade de análise.

6 O Instituto Histórico e Geográfico do Rio Grande do Sul (IHGRGS), referida instituição de custódia do acervo, se caracteriza como uma instituição privada sem fins lucrativos, fundada a 05 de agosto de $1920^{2}$, cuja finalidade é promover estudos e investigações sobre História, Geografia, Arqueologia, Filologia, Antropologia e campos correlatos do conhecimento, principalmente centrados no Rio Grande do Sul. Sua principal finalidade é preservar a "memória rio-grandense através de fundos documentais e acervos bibliográficos que servem, também, para embasar as investigações e a construção de massa crítica sobre seu objeto de trabalho" ${ }^{3}$. Possui uma sede no centro de Porto Alegre, que faz parte do patrimônio recebido do governo do Estado em 1948 e foi inaugurada em 25 de março de 1972. A edificação conta com três andares: a Sala de Pesquisa e a Biblioteca Tomás Carlos Duarte situam-se no $1^{\circ}$ andar; a Sala dos Arquivos, a Biblioteca geral e a Mapoteca, no $2^{\circ}$ andar e o Auditório para 150 pessoas ocupa o $3^{\circ}$ andar. $O$ Guia de arquivos pessoais e coleções do IHGRGS, publicado em $2013^{4}$, registra 72 Fundos (arquivos pessoais de intelectuais, políticos, historiadores, literatos gaúchos) e 9 coleções. Porém, de lá para cá, outros fundos foram associados, assim como obras à sua biblioteca. Os conteúdos do Acervo SJP estão dispersos em vários locais do Instituto: a biblioteca sem catalogação está 
em prateleiras da Biblioteca Geral do segundo andar; as pastas suspensas no arquivo deslizante do segundo andar; as 56 caixas estão em uma pequena sala também do segundo andar, chaveada; os 32 fichários com transcrição de jornais do século XIX e início do XX estão na sala do presidente do IHGRHS. Embora bem protegidos, o fundo documental que pertenceu à historiadora e pesquisadora Sandra Pesavento e sua biblioteca precisam de uma organização mais condizente com sua importância.

7 No ano que inicia, 2019, ganhamos um financiamento pelo edital Universal do CNPq do Brasil para organizarmos o acervo, catalogando sua biblioteca, classificando os documentos e digitalizando-os a fim de torná-los acessíveis à comunidade acadêmica e aos interessados em geral, o que se dará em parceria da Universidade Federal de Goiás e o Instituto Histórico e Geográfico do Rio Grande do Sul. O projeto de pesquisa, com 10 participantes, terá a duração de 36 meses e pretende, além da organização do acervo, promover eventos e realizar publicações e produtos culturais que divulguem seu conteúdo, assim como promovam a memória da historiadora e de sua obra.

Em anexo a este texto, estão colocadas algumas imagens do acervo, desde o início de sua constituição até a forma como se apresenta hoje, além de alguns documentos.

\section{Imagens do acervo}

Fotos do Acervo Sandra Jatahy Pesavento (SJP), no Instituto Histórico e Geográfico do Rio Grande do Sul

10 Todas as fotos são de propriedade de Nádia Maria Weber Santos

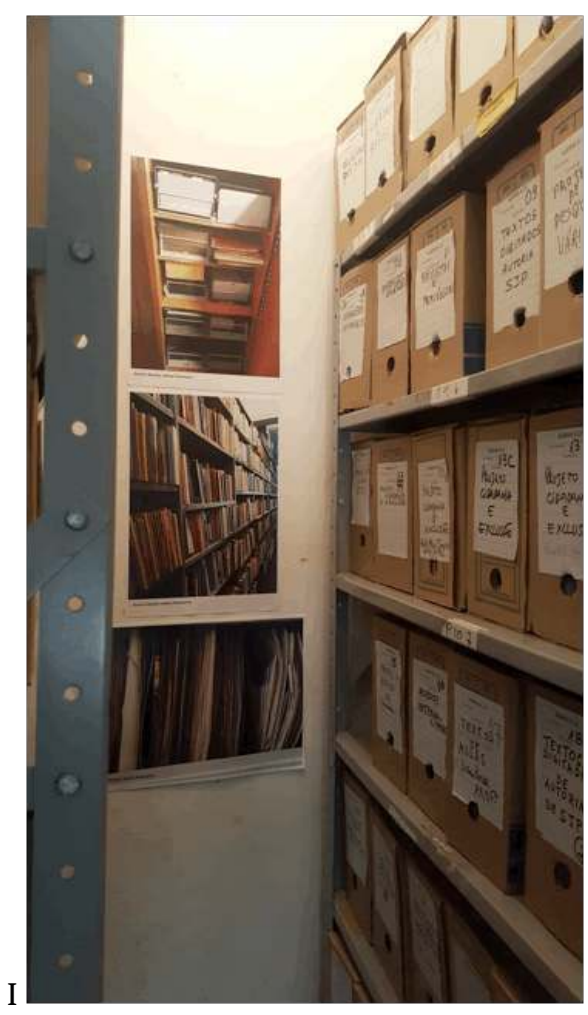

Imagem 1 
Fundo documental - caixas (sala especial)

12

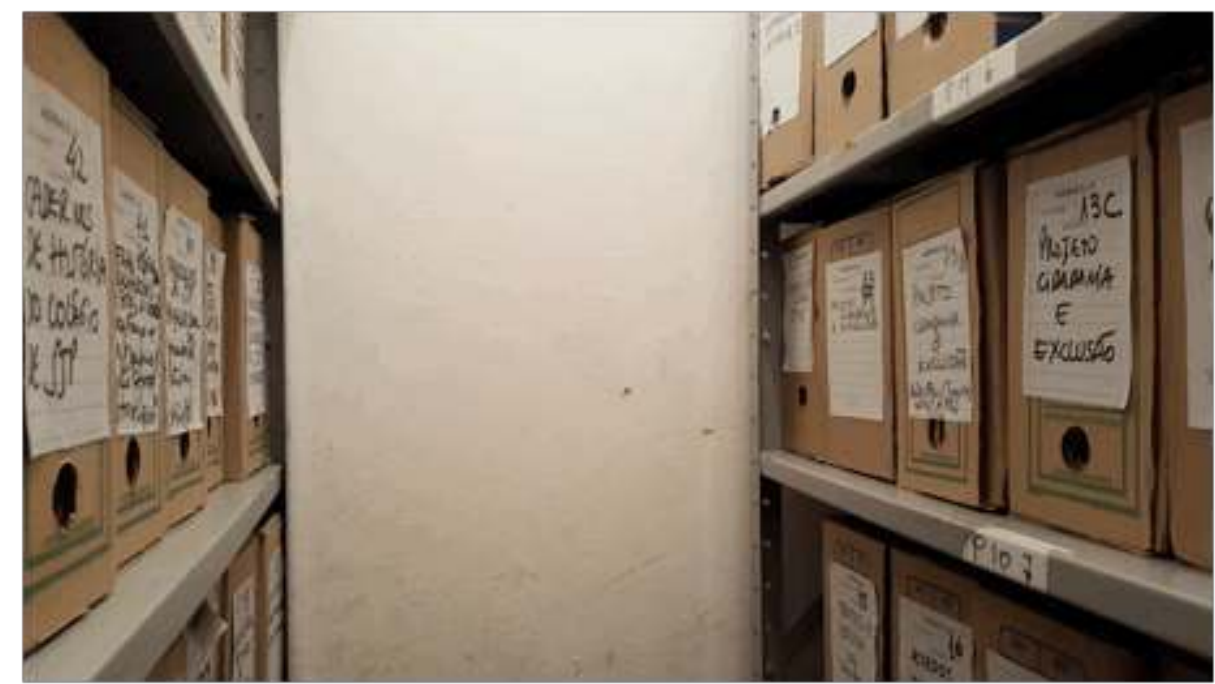

Imagem 2

Fundo documental - caixas (sala especial)

14

15

16

17



Imagem 3 
Fundo documental - pastas suspensas

18

19

20

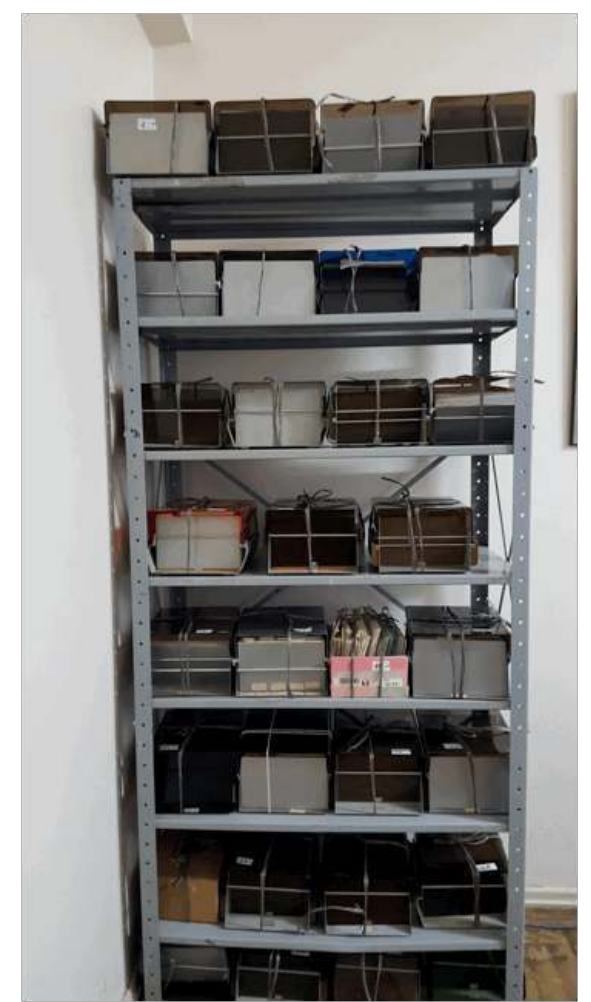

Imagem 4

Fundo documental - fichários
21

22 


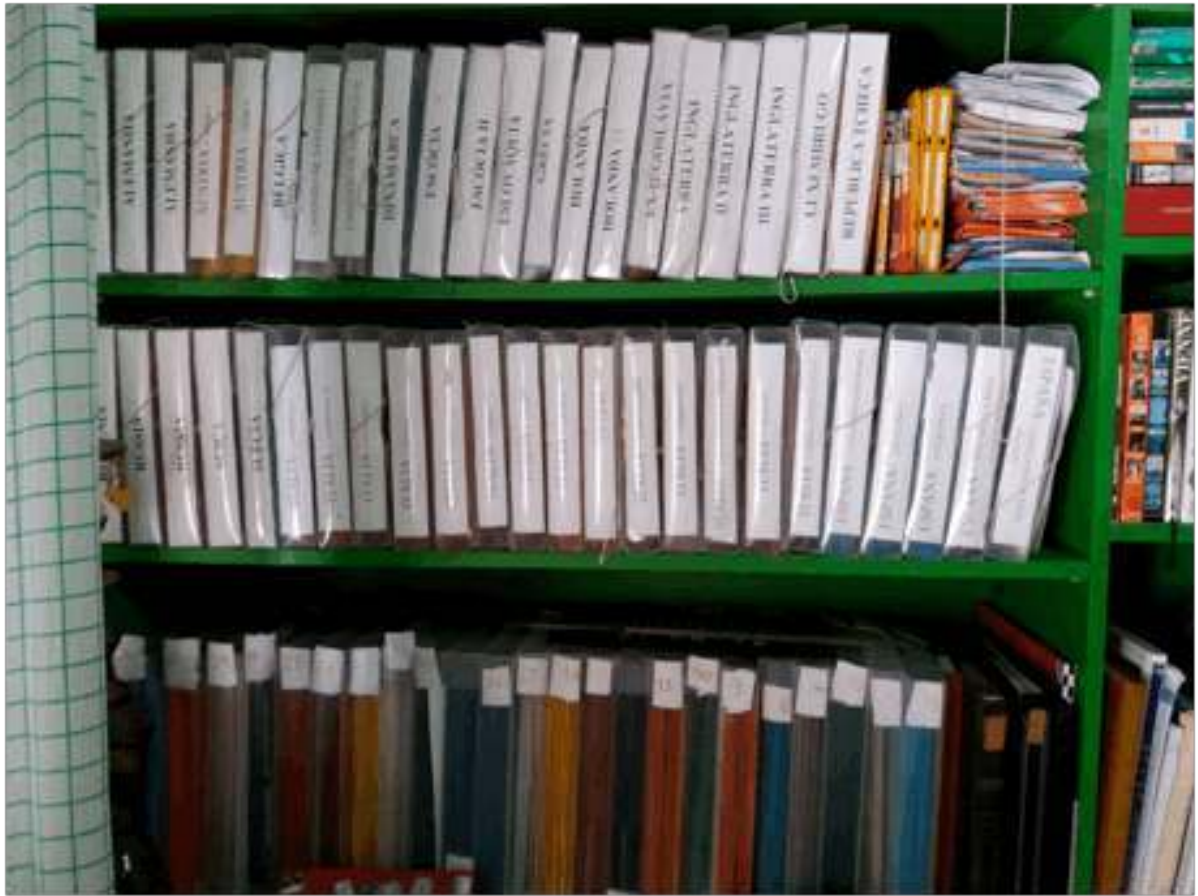

27

Imagem 5

Fundo documental - álbuns de fotografias 


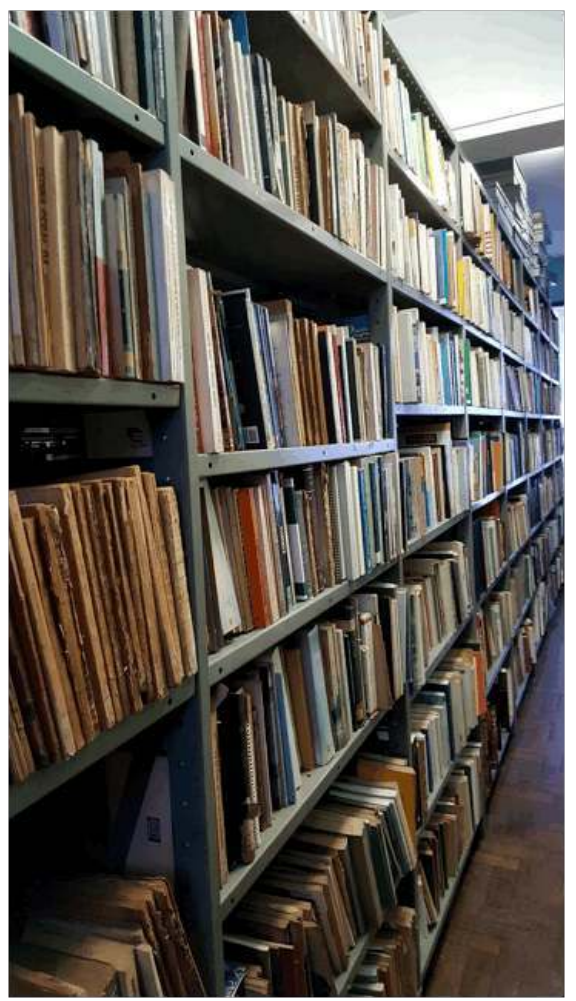

Imagem 6

Coleção Bibliográfica - Biblioteca Sandra Jatahy Pesavento

33 


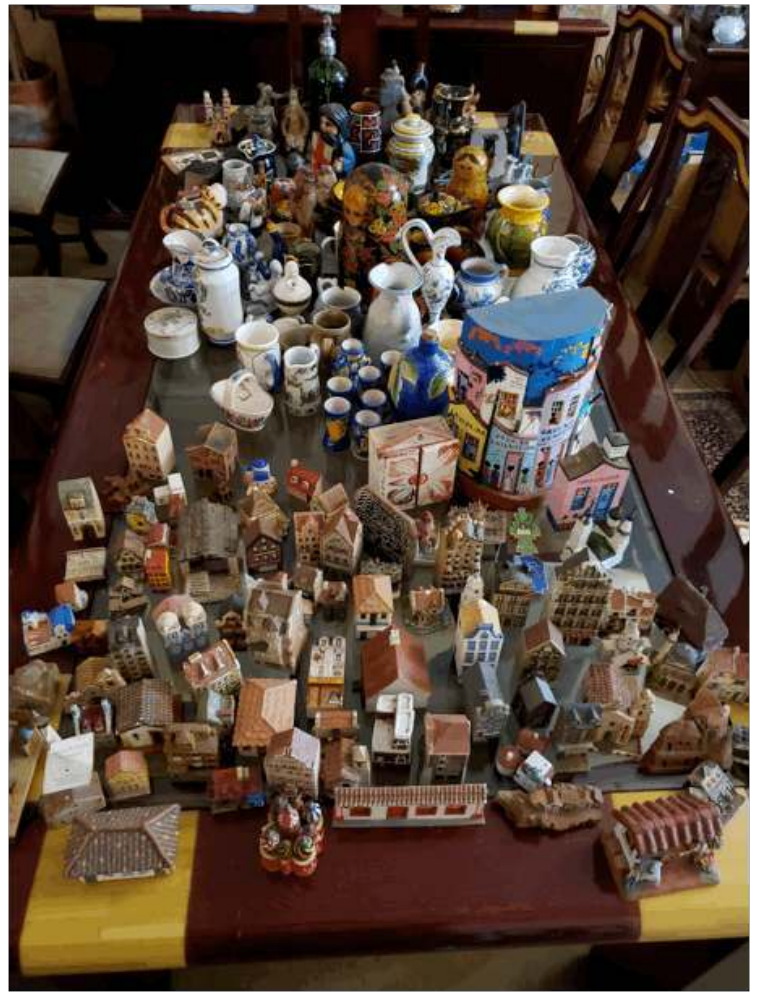

34

Imagem 7

Acervo museológico - Objetos tridimensionais (fase de inventário) 




Imagem 8

Documento do Acervo - Caixa 33 A (plano de aula de pós-graduação)

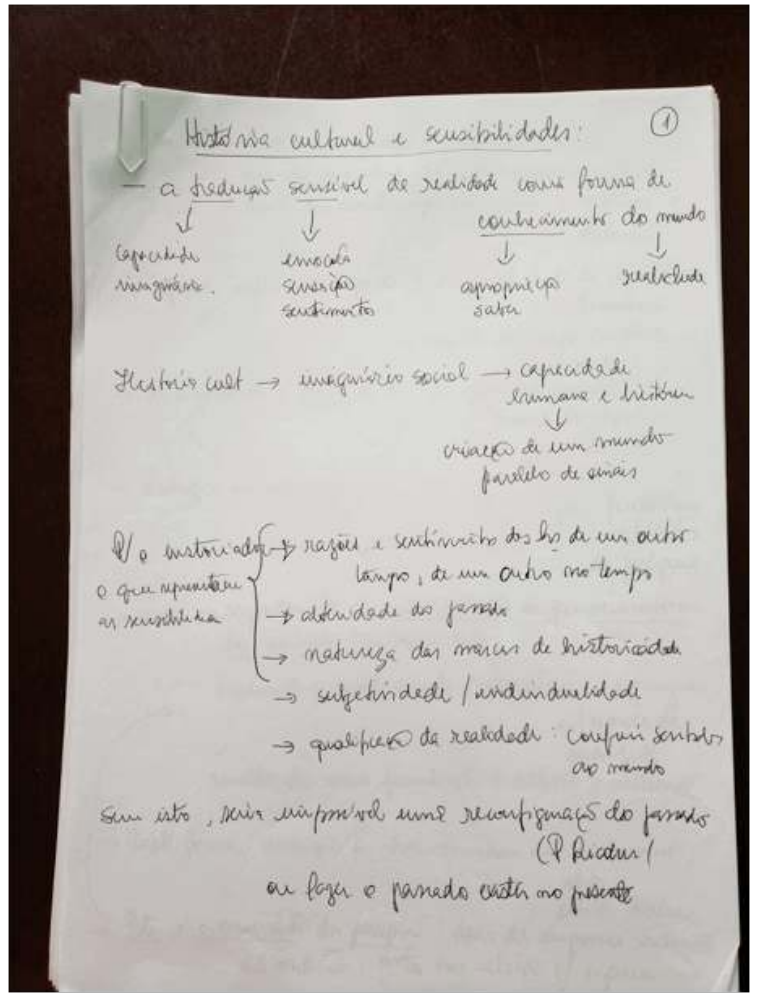


Imagem 9

Documento do Acervo - Caixa 33 A (estudos, plano para livro)

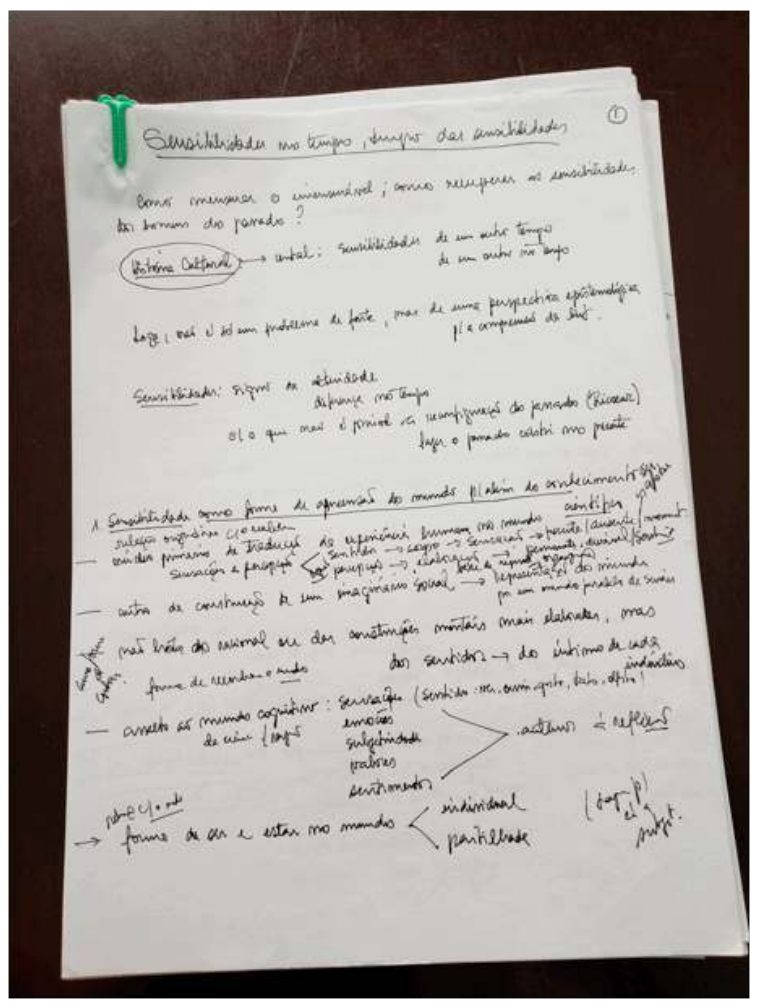

Imagem 10

Documento do Acervo - Caixa $33 \mathrm{~A}$ (manuscrito de artigo)

\section{NOTAS DE FIM}

1. 0 endereço do site é http://sandrapesavento.org/ . Acessado em 02-09-2018.

2. Fundadores: Octavio Augusto de Faria, capitão Manoel Joaquim de Faria Corrêa, tenente Emílio Fernandes de Souza Docca, Afonso Aurélio Porto e o Pe. João Batista Hafkemeyer, juntamente com o Desembargador Florêncio de Abreu e o apoio decisivo do Governador Borges de Medeiros. 
3. Informações retiradas do site do IHGRGS. Para mais informações consultar o site http:// www.ihgrgs.org.br.

4. http://www.ihgrgs.org.br/arquivo/GuiaAcervoIHG_site.pdf

\section{RESUMOS}

O material completo do Acervo Sandra Jatahy Pesavento depositado no Instituto Histórico e Geográfico do Rio Grande do Sul (IHGRGS) desde final de 2014, tem em torno de 114 metros lineares e, dentre os diversos focos de conteúdos, que perpassam as várias fases da historiadora e pesquisadora da UFRGS.

Le matériel complet de la collection Sandra Jatahy Pesavento, déposé à l'Institut d'histoire et géographique de Rio Grande do Sul depuis fin 2014, est d'environ 114 mètres linéaires et, il est possible trouver, parmi les différents contenus abordés, des documents qui traversent les différentes phases de l'historien et chercheur de l'UFRGS.

\section{ÍNDICE}

Palavras-chave: Arquivo pessoal. Sensibilidades. Teoria e Metodologia. Sandra Pesavento. História Cultural.

Mots-clés: Archives personnelles. Sensibilités. Théorie et méthodologie

\section{AUTOR}

\section{NÁDIA MARIA WEBER SANTOS}

Dra. em História. Professora do PPG em Performances Culturais da UFG (Universidade Federal de Goiás). Autora de vários livros e artigos na área da História Cultural, com ênfase em História da Loucura e da Psiquiatria, Memória Social, Sensibilidades, Arquivos pessoais e Performances Culturais. Destacam-se as obras individuais: Histórias de vidas ausentes: a tênue fronteira entre a saúde e a doença mental (2 $2^{\mathrm{a}}$ edição ampliada e revista, SP: Edições Verona, 2013); Histórias de sensibilidades e narrativas da Loucura (Porto Alegre, Ed. da Universidade/ UFRGS, 2008) 